\title{
The Cost-effectiveness of a Flash Glucose Monitoring System for Management of Patients with Type 2 Diabetes Receiving Intensive Insulin Treatment in Sweden
}

\author{
S Pinar Bilir, ${ }^{1}$ Richard Hellmund, ${ }^{2}$ Elizabeth Wehler, ${ }^{3}$ Huimin Li, ${ }^{4}$ Julie Munakata ${ }^{1}$ and Mark Lamotte ${ }^{5}$ \\ 1. IQVIA, San Francisco, CA, US; 2. Abbott Diabetes Care, Alameda, CA, US; 3. IQVIA, Plymouth Meeting, PA, US; 4. IQVIA, Fairfax, VA, US, \\ 5. IQVIA Corporate Village, Zaventem, Belgium
}

DOI: https://doi.org/10.17925/EE.2018.14.2.80

\begin{abstract}
F lash glucose monitoring, an alternative to traditional self-monitoring of blood glucose (SMBG), prevents hypoglycaemic events without impacting glycated haemoglobin (REPLACE trial). Given the potential benefits, this study assessed the cost-effectiveness of using flash monitoring versus SMBG alone in patients with type 2 diabetes (T2D) receiving intensive insulin treatment in Sweden.Methods: This study used the IQVIA CORE Diabetes Model (IQVIA CDM, V8.5) to simulate the impact of flash monitoring versus SMBG over 40 years from the Swedish societal perspective. Baseline characteristics, intervention effects, and resource utilisation were derived from REPLACE; literature and Tandvårds-Läkemedelförmånsverket (TLV) sources informed utilities and costs. Scenario analyses explored the effect of key base case assumptions. Results: In base case analysis, direct medical costs for flash monitoring use were SEK1,630,586 (€158,523) versus SEK1,459,394 (€141,902) for SMBG use. Flash monitoring led to 0.56 additional quality-adjusted life years (QALYS; 6.21 versus 5.65 SMBG) for an incremental cost-effectiveness ratio (ICER) of SEK306,082/QALY (€29,762/QALY). ICERS for all scenarios remained under SEK400,000/QALY (€38,894/QALY). Conclusions: Hypoglycaemia and health utility benefits due to flash glucose monitoring may translate into economic value compared to SMBG. With robust results across scenario analyses, flash monitoring may be considered cost-effective in a Swedish population of T2D intensive insulin users.
\end{abstract}

\section{Keywords}

Type 2 diabetes, glucose monitoring,

cost, cost analysis, economic analysis

Disclosure: Richard Hellmund is a full-time employee of Abbott Diabetes Care and is a stock holder. S Pinar Bilir, Elizabeth Wehler, Huimin Li, Julie Munakata and Mark Lamotte are employed by IQVIA, Inc., which received payment from Abbott Diabetes Care to provide health economic consulting services.

Review Process: Double-blind peer review.

Compliance with Ethics: This study did not involve any studies with human or animal subjects performed by any of the authors.

Authorship: All named authors meet the criteria of the International Committee of Medical Journal Editors for authorship for this manuscript, take responsibility for the integrity of the work as a whole and have given final approval for the version to be published.

open Access: This article is published under the Creative Commons Attribution Noncommercial License, which permits any non-commercial use, distribution, adaptation and reproduction provided the original author(s) and source are given appropriate credit. () The Authors 2018.

Received: 12 July 2018

Accepted: 7 August 2018

Citation: European Endocrinology, 2018;14(2):80-5

Corresponding Author: S Pinar Bilir, IQVIA,

425 Market St, Floor 7, San Francisco CA

94105 US. E: pinar.bilir@iqvia.com

Support: This work was supported

by Abbott Diabetes Care.
Given the global nature of the diabetes epidemic, ${ }^{1}$ this condition is of public health importance in Sweden. ${ }^{2}$ National prevalence in Sweden is approximately $7.0 \%$, based on a recent estimate, ${ }^{1}$ and approximately $90 \%$ of cases are type 2 diabetes (T2D). ${ }^{1,3}$ This prevalence figure, which is growing over time despite stable incidence, ${ }^{4}$ has a direct impact on overall population health. In 2015, over 3,000 deaths were attributed to diabetes in Sweden. ${ }^{1}$ Moreover, patients with diabetes are at higher risk for disabling or life-threatening health problems than non-diabetic patients. ${ }^{5}$

A high burden exists from an economic perspective, as well. Recent figures indicate that Sweden spent over US $\$ 8,000$ per diabetes patient annually on managing diabetes. ${ }^{1}$ In addition to the costs of managing diabetes, poor glycaemic control is associated with higher additional healthcare costs, both to treat short-term hypoglycaemic events and to manage longer-term macro- and microvascular complications. ${ }^{6,7}$ The total cost for identified patients with T2D in the Prescribed Drug Registry in 2014 was nearly $€ 1.3$ billion, ${ }^{8}$ and this does not account for any additional societal burden associated with lost productivity or caregiver time. ${ }^{19,10}$

Some patients with T2D may require insulin when diet and exercise and other medications become inadequate to control blood glucose. ${ }^{1}$ The trade-off between insulin helping to reduce glycated haemoglobin ( $\mathrm{HbA} 1 \mathrm{c})$ and an increased risk of hypoglycaemic events or related complications has been well-established. ${ }^{11}$ Frequent monitoring of glucose levels allows patients to more appropriately manage blood glucose. ${ }^{1,12}$ Self-monitoring of blood glucose (SMBG) is the current standard of care for glucose monitoring; the European Consensus Statement recommends 4-8 times daily, ${ }^{13}$ while the American Diabetes Association (ADA) suggests 6-10 times per day for patients on intensive insulin therapy. ${ }^{14}$ However, many people do not monitor glucose at these recommended rates. ${ }^{15-18}$ SMBG adherence may be negatively impacted by factors such as discomfort with obtaining a blood sample, inconvenience of carrying testing kits around, perceived social stigma, needle phobia, and difficulty in interpreting results. ${ }^{19-23}$ Furthermore, SMBG provides data for only a single point in time, conveying relatively limited information on glucose levels and variability, which can impact clinicians' recommendations for therapy change. ${ }^{24}$ Although continuous monitoring is more informative, it is not universally reimbursed and applied due to expense..$^{23,25}$ 
Flash glucose monitoring, an alternative to traditional blood glucose monitoring, uses a sensor worn by the patient to provide continuous collection of interstitial glucose data. Passing the system's reader over the sensor at any time will show the current reading, a trend arrow, and the past 8 hours of data. Freestyle Libre ${ }^{\mathrm{TM}}$ (Abbott Diabetes Care, Witney, UK), a flash glucose monitoring system, was recently tested in an intensively insulin-treated T2D population in the REPLACE study. ${ }^{26}$

The REPLACE trial was a 6-month, multicentre, randomised controlled trial of the flash monitoring system versus SMBG in adults with T2D and HbA1c 7.5-12\% (58-108 mmol/mol), who were using multiple daily injection therapy or continuous subcutaneous insulin infusion for at least 6 months prior to enrolment. The study found clinical benefits such as a $27.7 \%$ reduction in measured hypoglycaemia $<70 \mathrm{mg} / \mathrm{dl}$ for flash monitoring compared to SMBG, without raising HbA1c levels. ${ }^{26}$

Given potential clinical benefits of intervention and potential associated decrease in resource utilisation, this study sought to assess the value of investment in using flash monitoring instead of routine SMBG via costeffectiveness analysis for patients with $\mathrm{T} 2 \mathrm{D}$ receiving intensive insulin treatment in Sweden.

\section{Research design and methods}

The present study was performed using version 8.5 of the IQVIA CORE Diabetes Model (IQVIA CDM).

\section{IQVIA CDM summary description}

The IQVIA CDM is a non-product specific internet application to assess the long-term health outcomes and economic consequences of interventions for Type 1 diabetes (T1D) or T2D. The underlying mathematical engine includes diabetes complication sub-modules that combine Markov techniques with Monte Carlo simulation, running simultaneously to capture outcomes associated with the treatments of interest. These sub-modules interact, and each patient profile is updated at the end of each 1-year cycle to account for the events across all submodules. The model captures differences in life expectancy, qualityadjusted life years (QALYS), costs, cumulative incidences of complication events due to intervention effects on diabetes-related adverse events, as well as $\mathrm{HbA} 1 \mathrm{C}$ levels and other physiological parameters that affect risks of major diabetes complications. The model has been published previously in detail, and it has been extensively validated against clinical and epidemiological studies. ${ }^{27,28}$

For this study, HbA1c progression reflects the Swedish National Diabetes Registry, while HbA1c-dependent adjustments reflect the United Kingdom Prospective Diabetes Study risk engine. ${ }^{29-31}$

Analyses took a Swedish societal perspective, evaluating costs and effects over a lifetime horizon (40 years, approximate lifetime from age at model entry). Swedish non-specific mortality information from the World Health Organisation was included. ${ }^{32}$ Costs and effects were discounted at $3 \%$ according to Swedish guidance. ${ }^{33}$ All analyses were run with 1,000 patients for 1,000 iterations.

\section{Model inputs \\ Cohort details}

The model cohort was designed to represent the REPLACE trial population (Table 1), ${ }^{26,34-36,44,61}$ to ensure appropriate alignment with intervention effects. Some cohort characteristics were unavailable in the trial data, and therefore published sources were used to supplement as needed.

\section{Intervention effects}

Intervention effects used in analyses are found in Table 2. Although no significant differences were seen in effect on HbA1C in the REPLACE trial, trial-based decreases by end of study of $0.29 \%$ (standard deviation [SD] $0.78 \% ; 3.19 \mathrm{mmol} / \mathrm{mol}$ [SD 8.58]) in the flash monitoring arm and $0.31 \%$ (SD 0.78\%; $3.41 \mathrm{mmol} / \mathrm{mol}$ [SD 8.58]) in the SMBG arm were implemented into the model.

Hypoglycaemia event rates were likewise implemented as intervention effects; the analysis assumes major (or severe) events require thirdparty intervention, and minor (or non-severe) events require no outside care. To ensure alignment with available data on costs of hypoglycaemic events, rates were obtained from the literature. The rate for major hypoglycaemic events from a recent meta-analysis was used for both the flash monitoring and SMBG arms; ${ }^{37}$ no difference was assumed for the purpose of the model because the REPLACE study was not designed to detect differences in safety outcomes such as severe hypoglycaemia. The minor hypoglycaemia rate reported in the same meta-analysis was used for SMBG. Because the REPLACE trial demonstrated a relative effect on non-severe hypoglycaemia due to flash monitoring, this relative reduction was applied to the meta-analysis minor hypoglycaemia rate to calculate a flash monitoring rate.

\section{Intervention-related resource utilisation}

Intervention-related resource use was derived from the REPLACE trial. For patients using flash monitoring, the analysis assumed 109.5 test strips/year, 251.85 lancets/year, and 85.2 units of insulin/day, as well as 26 sensors per year and an extra physician visit in the first year. In the SMBG arm, parallel resource use assumptions included 1,095 test strips/year, 459.9 lancets/year, and 87.8 units of insulin/day. All patients received $1,500 \mathrm{mg}$ of metformin daily.

\section{Unit costs}

Table $3^{38-42}$ shows the key cost inputs for the analyses, including intervention-related unit costs, total intervention costs, and costs for key acute events; Appendix 1 shows the full list of costs used in the analyses. Intervention-specific consumables reflect lowest-cost items available from Tandvårds-Läkemedelförmånsverke (TLV), ${ }^{42}$ and all costs were inflated as needed to 2016 currency using the consumer price index for Sweden from the Organization for Economic Co-operation and Development. ${ }^{43}$

\section{Utilities}

Utilities and disutilities (Table 1) were based on published literature. For the minor hypoglycaemic disutility, values were separately calculated for the flash monitoring and SMBG arms using a diminishing disutilities approach from Lauridsen et al., 2014. ${ }^{44}$ The literature shows that for the first few minor hypoglycaemic events, patients experience relatively high disutilities; as the patient has more events, the disutility per event diminishes. Therefore, the average disutility per event is contingent on the total rate of minor hypoglycaemic events. A treatment-related utility benefit of 0.03 was applied to the flash monitoring arm based on a recent time trade off study. ${ }^{45}$ Sensitivity analyses explored this concept further.

\section{Analyses}

The base case analyses compare flash monitoring use against routine SMBG use, utilising default inputs from Table 2. Additional scenario analyses (summarised in Table 4) explored the impact of key model assumptions. These include a scenario to test the impact 


\section{Table 1: Cohort characteristics}

\begin{tabular}{|c|c|c|}
\hline & Default value & Source \\
\hline \multicolumn{3}{|l|}{ Demographics } \\
\hline Start age (years, mean [SD]) & $59.2(10.3)$ & Haak et al., $2017^{26}$ \\
\hline Duration of diabetes (years, mean [SD]) & $17.0(8.0)$ & Haak et al., $2017^{26}$ \\
\hline Male (\%) & $67.0 \%$ & Haak et al., $2017^{26}$ \\
\hline \multicolumn{3}{|l|}{ Baseline risk factors } \\
\hline $\mathrm{HbA} 1 \mathrm{C}(\%$, mean $[S D])$ & $8.68(1.00)$ & Haak et al., $2017^{26}$ \\
\hline Systolic blood pressure (mmHg, mean [SD]) & $137.0(16.0)$ & Haak et al., $2017^{26}$ \\
\hline Total cholesterol (mg/dL, mean [SD]) & $186.0(45.0)$ & Haak et al., $2017^{26}$ \\
\hline $\mathrm{HDL}$ (mg/dL, mean [SD]) & $49.0(14.0)$ & Haak et al., $2017^{26}$ \\
\hline LDL (mg/dL, mean [SD]) & $99.0(38.0)$ & Haak et al., $2017^{26}$ \\
\hline Triglycerides (mg/dL, mean [SD]) & $208.0(199.0)$ & Haak et al., $2017^{26}$ \\
\hline Estimated glomerular filtration rate (mean [SD]) & $77.5(15.0)$ & Hayes et al., $2013^{34}$ \\
\hline Haemoglobin (mean, SD) & $14.5(1.3)$ & Hayes et al., $2013^{34}$ \\
\hline White blood cells (mean [SD]) & $6.8(1.8)$ & Hayes et al., $2013^{34}$ \\
\hline Heart rate (bpm, mean [SD]) & $72.0(12.0)$ & Hayes et al., $2013^{34}$ \\
\hline Proportion smoker (\%) & $14.0 \%$ & Abbott Diabetes Care, $2016^{35}$ \\
\hline Cigarettes/day & 3 & Abbott Diabetes Care, $2016^{35}$ \\
\hline Alcohol consumption (oz/week) & 0.87 & Abbott Diabetes Care, $2016^{35}$ \\
\hline \multicolumn{3}{|l|}{ Racial characteristics (\%) } \\
\hline Prop. White & $96.40 \%$ & Abbott Diabetes Care, $2016^{35}$ \\
\hline Prop. Black & $1.30 \%$ & Abbott Diabetes Care, $2016^{35}$ \\
\hline Prop. Hispanic & $0.00 \%$ & Abbott Diabetes Care, $2016^{35}$ \\
\hline \multicolumn{3}{|l|}{ Utilities } \\
\hline Baseline & 0.785 & Clarke et al., $2002^{36}$ \\
\hline Major hypoglycaemic event & $-0.012^{a}$ & Currie et al., $2013^{61}$ \\
\hline Minor hypoglycaemic event (flash monitor) & $-0.00408^{b}$ & Lauridsen et al., $2014^{44}$ \\
\hline Minor hypoglycaemic event (SMBG) & $-0.00329^{c}$ & Lauridsen et al., $2014^{44}$ \\
\hline
\end{tabular}

${ }^{a}$ Converted to annual value from published 3-month value (Currie 2006); ${ }^{\circ} \mathrm{Calculated} \mathrm{on} \mathrm{the} \mathrm{basis} \mathrm{of} \mathrm{a} \mathrm{non-severe} \mathrm{hypog/ycaemic} \mathrm{event} \mathrm{rate} \mathrm{of} \mathrm{1,685} \mathrm{per} 100$ patient-years, ${ }^{44}$ ${ }^{c} \mathrm{Calculated}$ on the basis of a non-severe hypoglycaemic event rate of 2,331 per 100 person-years (Lauridsen 2014). bpm = beats per minute; $\mathrm{HbA1C}=$ glycated haemoglobin: $H D L=$ high-density lipoprotein; $L D L=$ low-density lipoprotein; Prop = proportion; SD = standard deviation; SMBG = self-monitoring of blood glucose.

\section{Table 2: Treatment effects}

\begin{tabular}{|c|c|c|c|}
\hline & Flash monitoring & SMBG & Source \\
\hline \multicolumn{4}{|l|}{ Physiological parameters } \\
\hline Change from baseline HbA1C (mean [SD]) & $0.29 \%(0.78 \%)$ & $0.31 \%(0.78 \%)$ & Haak et al., $2017^{26}$ \\
\hline \multicolumn{4}{|l|}{ Adverse events } \\
\hline Major hypoglycaemic events (/100 PYs) & 105.00 & 105.00 & Edridge et al., $2015^{37}$ \\
\hline Minor hypoglycaemic events (/100 PYs) & 1685.00 & 2331.00 & $\begin{array}{l}\text { Edridge et al., } 2015^{37} \\
\text { Abbott Diabetes Care, } 2016^{35}\end{array}$ \\
\hline \multicolumn{4}{|l|}{ Other } \\
\hline Annual utility score associated with treatment (mean [95\% CI]) & $0.03(0.023,0.038)$ & 0.00 & Matza et al., $2017^{45}$ \\
\hline
\end{tabular}

$\mathrm{Cl}=$ confidence interval; $\mathrm{HDA} 1 \mathrm{C}=$ glycated haemoglobin; $\mathrm{PY}=$ patient-year; $\mathrm{SD}=$ standard deviation; $\mathrm{SMBG}=$ self-monitoring of blood glucose.

of incorporating non-intervention resource utilisation as observed in the trial in the first year of the model. In this scenario, all-cause trialbased use of resources such as ambulances, emergency room visits, and hospitalisation were implemented. Among intensive insulin users it is not possible to establish whether resource use is disease-specific due to older age and increase in comorbidities and complications, ${ }^{46-48}$ and thus all-cause resource use is appropriate for scenario evaluation. In the event that these differences were driven by hypoglycaemic events, the assigned hypoglycaemic event costs were removed from the model to avoid potential double-counting. 
Table 3: Intervention costs

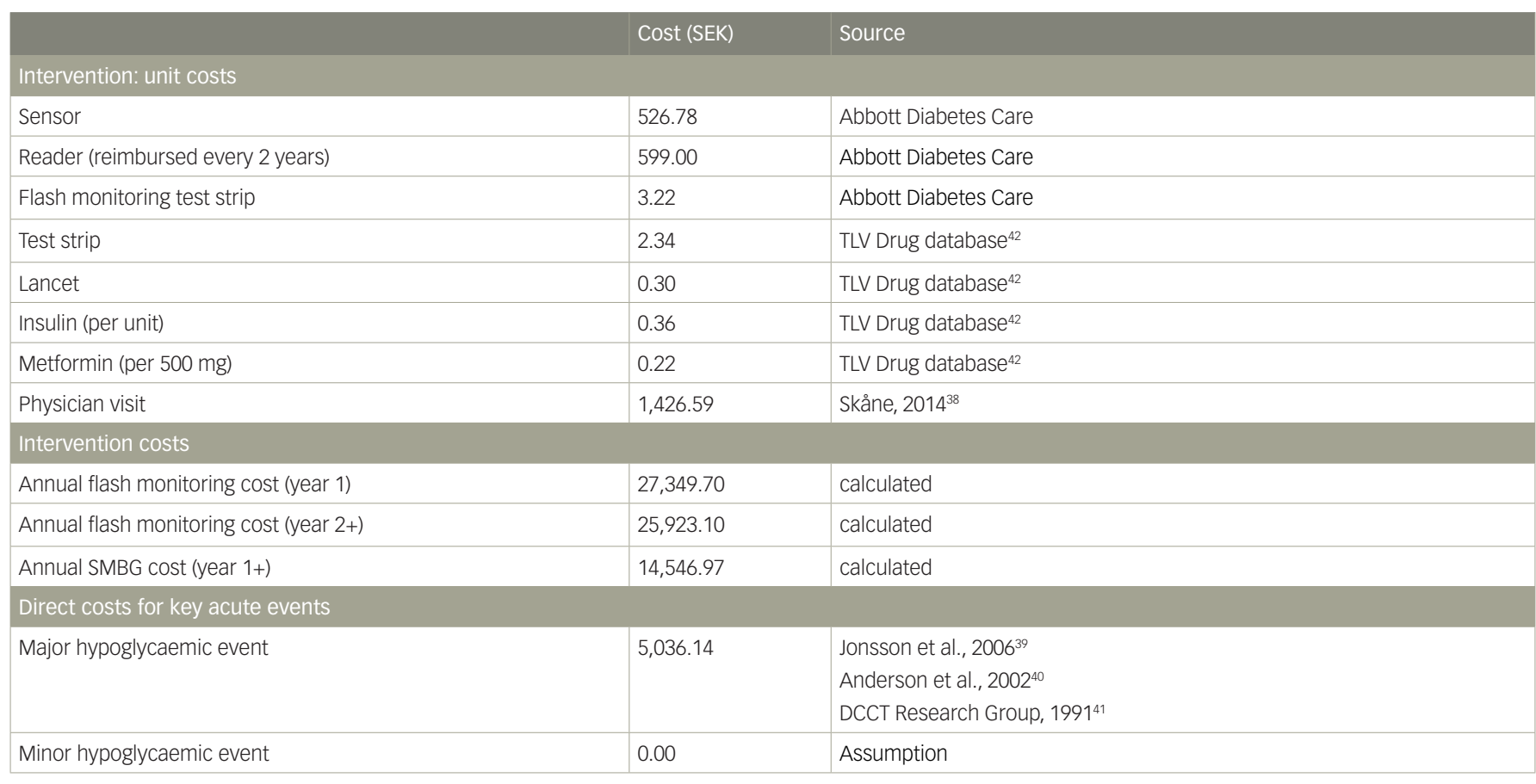

DCCT = Diabetes Control and Complications Trial; SMBG = self-monitoring of blood glucose; TLV = Tandvårds-Läkemedelförmånsverke.

Table 4: Base case results

\begin{tabular}{|l|l|l|l|}
\hline & Flash monitoring & SMBG & Incremental \\
\hline Costs & SEK 1,630,586 & SEK 1,459,394 & SEK 171,192 \\
\hline LYS & 14.33 & 14.34 & -0.010 \\
\hline QALYS & 6.21 & 5.65 & 0.560 \\
\hline ICER/LY & & & NA \\
\hline ICER/QALY & & & SEK 306,082 \\
\hline
\end{tabular}

ICER = incremental cost-effectiveness ratio; $L Y=$ life year; $Q A L Y=$ quality-adjusted life year; $S M B G=$ self-monitoring of blood glucose.

Additional scenarios examined the impact of varying the utility benefit for flash monitoring over a range of 0.023-0.038 (95\% confidence interval around base case), and to explore the impact of varying discount rates and time horizon. A final scenario leveraged crosssectional real-world evidence from 50,000 flash monitoring sensors, ${ }^{49}$ rather than trial-based values. This evidence showed that average scan frequency is $16 /$ day for flash monitoring users, in comparison with an average of 2.7 tests/day for T2D SMBG users. ${ }^{12} \mathrm{~A}$ measured difference of $0.94 \%$ between the average $\mathrm{HbA} 1 \mathrm{C}$ associated with 16 scans/day and that associated with typical SMBG use was used to explore this potential additional benefit of flash monitoring. This reflects an assumption that flash monitoring may lead to increased glucose testing and result in decreased $\mathrm{HbA} 1 \mathrm{C}$.

\section{Results}

Disaggregated results, including total costs and QALYs per strategy, are reported in Table 4. In base case analysis, a difference of SEK171,192 in direct medical costs were attributable to flash monitoring (SEK1,630,586) for flash monitoring versus SEK1,459,394 [€141,902] for SMBG). Total life years (LYS) were nearly equivalent (14.33 and 14.34 LYS for flash monitoring and SMBG, respectively), with the minor difference associated with the insignificant difference in HbA1C results from the REPLACE trial. When incorporating quality-adjustment, however, flash monitoring patients experience 0.56 more QALYS (6.21 versus 5.65, respectively) for an incremental cost-effectiveness ratio (ICER) of SEK306,082/QALY $(€ 29,762 / \mathrm{QALY})$. In terms of cost per hypoglycaemic event averted, the difference of 137.22 more minor hypoglycaemic events for SMBG patients led to a cost per minor event averted of SEK1,248.

Key scenarios that were evaluated to test the impact of assumptions or input values are reported in Figure 1. Flash monitoring dominates when real-world evidence is considered in the model. The highest ICER occurs when testing a lower potential utility benefit associated with flash monitoring.

\section{Discussion}

This first cost-effectiveness analysis of flash monitoring in patients with T2D using intensive insulin demonstrates that use of the flash monitoring system is associated with a modest impact on diabetes-related costs, and can be considered cost-effective compared to current standard of care for glucose monitoring (SMBG). Although SMBG is less costly overall (by SEK171,192), flash monitoring improves QALYS for patients, leading to a favourable cost-effectiveness ratio of just over SEK300,000/QALY. Continuous glucose monitoring systems may also be available for these patients; although, on an annualised basis, the list price of these systems is typically several times greater than the flash monitoring system. .0,51 $^{5}$ 
Figure 1: Scenario analysis results, showing ICERs in SEK/QALY

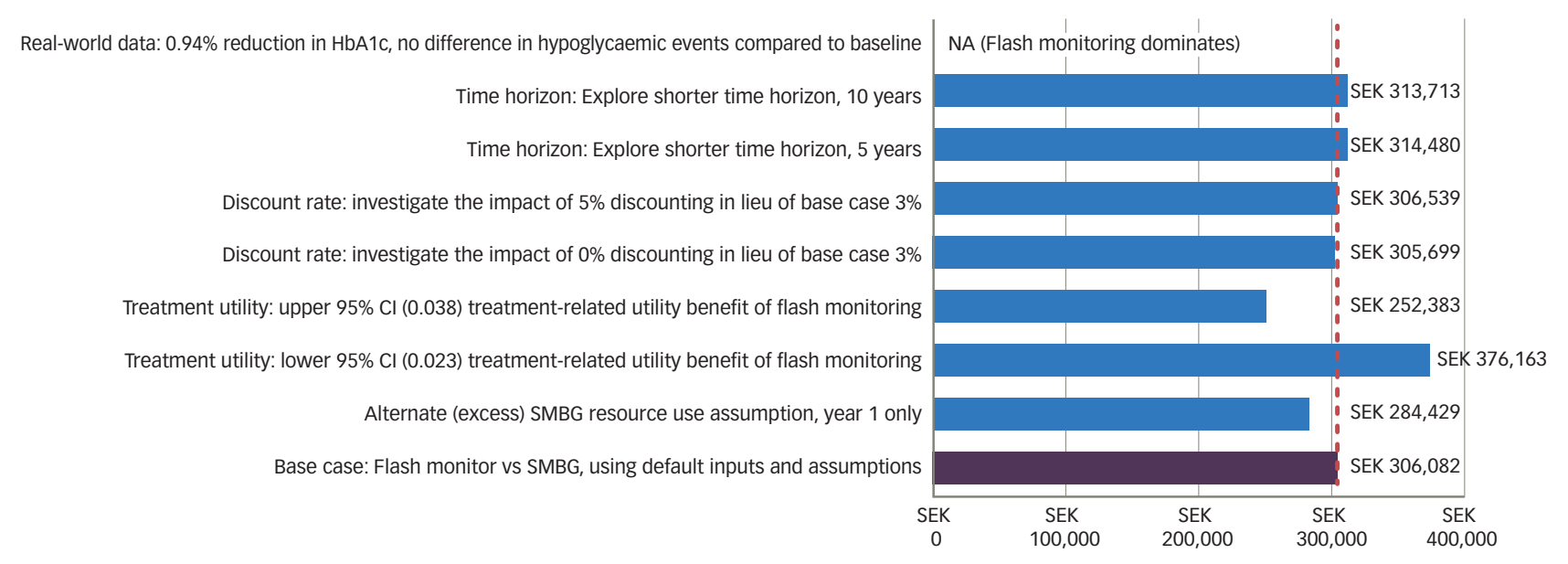

$\mathrm{Cl}=$ confidence interval; HDA1C = glycated haemoglobin; ICER = incremental cost-effectiveness ratio; QALY = quality-adjusted life year; SMBG = self-monitoring of blood glucose.

Flash monitoring may be considered good value for money regardless of type 1 or type 2 status for patients using this therapeutic approach, as this analysis joins evidence on the economic value for patients with T1D using intensive insulin. ${ }^{52}$ In the clinical trial setting, use of the system substantially reduced the number of hypoglycaemic events, including at low glucose thresholds ( $<55 \mathrm{mg} / \mathrm{dL}$ and $<40 \mathrm{mg} / \mathrm{dL}$ ), without raising HbA1C across populations. The observed clinical benefits may reflect improved management by patient access to convenient glucose measurement data. ${ }^{53}$

Through additional scenario analysis, results are robust to alternate assumptions. ICERS remained under published willingness-to-pay threshold ranges for Sweden. Although Sweden does not publish an explicit threshold, interventions have been accepted with an average ICER of $€ 36,000 / Q A L Y,{ }^{54}$ which is approximately SEK400,000 /QALY, and an 'informal threshold' of SEK500,000 has been identified in publications. ${ }^{55}$ Treatments for more severe conditions have been considered acceptable up to $€ 90,000 /$ QALY (SEK827,000/QALY). ${ }^{54,56}$

A number of limitations for this study must be acknowledged. The analysis assumes that non-severe hypoglycaemic events are not associated with the occurrence of other more severe events like severe hypoglycaemia, myocardial infarction and mortality. However, in the PREDICTIVE study, a high frequency of non-severe events was significantly associated with the occurrence of severe events; $;$ this would be particularly important to consider in an older population for whom avoiding hypoglycaemia is a therapeutic goal. ${ }^{58}$

Additionally, these analyses may not capture all health outcomes. For example, the risk of cardiovascular disease in the IQVIA CDM is based on HbA1C, together with lipid levels, blood pressure, co-morbidities, and body mass index. However, recent evidence has suggested that people experiencing hypoglycaemic events may be at an increased risk of cardiovascular disease. ${ }^{5,60}$ Although the baseline characteristics in that study may differ from our analysis, it raises the possibility that our analysis underestimates the value of reducing hypoglycaemic events.

The main clinical data and patient characteristics are taken from a 6-month trial, and may not exactly represent the real-world effects of the flash monitoring system or represent the T2D patient population using the flash monitoring system in the real world. However, there were no protocol-mandated monitoring or adjustments to therapy, and therefore the results may be considered generalisable. Supplemental exploratory analysis based on cross-sectional real-world data ${ }^{49}$ from patients using flash monitoring also suggest that results may be even better than implemented in the base case due to potential $\mathrm{HbA} 1 \mathrm{c}$ benefit in realworld use. Additionally, the trial-estimated reduction in hypoglycaemic events was based on sensor identification rather than symptoms; however, for this reason, the reduction in events was applied solely to the non-severe event rate, and that base rate was derived from the literature.

Our analysis simplified the treatment pathway faced by patients by assuming that glucose monitoring and insulin use do not change over time. Yet, in the absence of data, typical modelling practice is to assume that there is no difference associated with treatment; any insulin change applying to both strategies equally would not alter the conclusions of this study.

Additionally, current utility values may not fully represent the impact of using flash monitoring. The disutility associated with minor hypoglycaemic events is assumed to reflect the diminishing effect of each event as they become more frequent, as has been shown in recent research. ${ }^{44}$ However, the average value per event applying this technique is much smaller than that used in prior economic analyses, ${ }^{61}$ and therefore, the values used in this study are likely to be more conservative but also more realistic relative to other published values. Separately, in the treatment phase of REPLACE or during the subsequent openaccess phase of 6 months' duration, ${ }^{62}$ no safety concerns with flash monitoring were observed. Skin reactions were reported for nine (6.5\%) participants during the open-access phase and six participants (4.0\%) in the treatment phase (preceding 6 months). Based on this information, potential skin reactions are not considered to have a material impact on the results presented here.

Despite the limitations, this analysis provides insight into the economic value of flash monitoring use compared with SMBG in T2D intensive insulin users. With limited impact on overall costs yet substantial relative QALY improvements, as well as robust results across tested scenarios, flash monitoring may be considered cost-effective in a swedish population among T2D patients using intensive insulin. $\square$ 
1. International Diabetes Federation. IDF Diabetes Atlas, 8th edn. Brussels, Belgium: International Diabetes Federation, 2017.

2. Andersson A, Ahlbom A, Carlsson S. Diabetes prevalence in Sweden at present, and projections for year 2050. PLOS One. 2015:10:e0143084.

3. Maahs DM, West NA, Lawrence JM, et al. Chapter 1: epidemiology of type 1 diabetes. Endocrinol Metab Clin North Am. 2010;39:481-97.

4. Norhammar A, Bodegård J, Nystrom T, et al. Incidence, prevalence and mortality of type 2 diabetes requiring glucoselowering treatment, and associated risks of cardiovascular complications: a nationwide study in Sweden, 2006-2013. Diabetologia. 2016;59:1692-701.

5. Forbes JM, Cooper ME. Mechanisms of diabetic complications. Physiol Rev. 2013;93:138-88.

6. Gilmer TP, O'Connor PJ, Rush WA, et al. Predictors of health care costs in adults with diabetes. Diab Care. 2005;28:59-64.

7. Menzin J, Korn JR, Cohen J, et al. Relationship between glycaemic control and diabetes-related hospital costs in patients with type 1 or type 2 diabetes mellitus. J Manag Care patients with type 1 or type

8. Kalkan A, Bodegard J, Eriksson J, et al. Doubled healthcare costs of type 2 diabetes mellitus during years 2006-2014: nationwide cost-of-illness study in Sweden. Presented at: European Association for the Study of Diabetes (EASD) Annual Meeting. Munich, 12-16 September 2016

9. Hex N, Bartlett C, Wright D, et al. Estimating the current and future costs of type 1 and type 2 diabetes in the UK, including direct health costs and indirect societal and productivity costs Diabet Med. 2012;29:855-62.

10. Langa KM, Vijan S, Hayward RA, et al. Informal caregiving for diabetes and diabetic complications among elderly Americans. J Gerontol. 2002;57B:S177-86.

11. The effect of intensive treatment of diabetes on the development and progression of long-term complications in insulin-dependent diabetes mellitus. The Diabetes Control and Complications Trial Research Group. N Eng/ J Med. and Complication

12. Schutt $M, K e r n W$, Krause $U$, et al. Is the frequency of selfmonitoring of blood glucose related to long-term metabolic control? Multicentre analysis including 24,500 patients from 191 centres in Germany and Austria. Exp Clin Endocrinol Diabetes. 2006;114:384-8.

13. Schnell $\mathrm{O}$, Alawi $\mathrm{H}$, Battelino $\mathrm{T}$, et al. Consensus statement on self-monitoring of blood glucose in diabetes. Diabetes Stoffwechsel und Herz. 2009;18:3-7.

14. American Diabetes Association. Standards of medical care in diabetes - 2017. Diabetes Care. 2017:40:S1-135.

15. Lee WC, Smith E, Chubb B, Wolden ML. Frequency of blood glucose testing among insulin-treated diabetes mellitus glucose testing among insulin-treated dlabetes mellitus

16. Yeaw J, Lee WC, Aagren M, Christensen T. Cost of selfmonitoring of blood glucose in the United States among patients on an insulin regimen for diabetes. J Manag Care patients on an insulin

17. Yeaw J, Lee WC, Wolden ML, et al. Cost of self-monitoring of blood glucose in Canada among patients on an insulin regime for diabetes. Diabetes Ther. 2012;3:7

18. Elgart JF, Gonzalez L, Rucci E, Gagliardino JJ. Self-monitoring of blood glucose: use, frequency drivers, and cost in Argentina. Diabetes Sci Technol. 2014;8:1121-5,

19. Wagner J, Malchoff $C$, Abbott $G$. Invasiveness as a barrier to self-monitoring of blood glucose in diabetes. Diabetes Technol Ther. 2005:7:612-19.

20. Hortensius J, Kars MC, Wierenga WS. et al. Perspectives of patients with type 1 or insulin-treated type 2 diabetes on selfmonitoring of blood glucose a qualitative study. BMC Public Health. 2012;12:1-11.

21. Vincze $G$, Barner $J C$, Lopez $D$. Factors associated with adherence to self-monitoring of blood glucose among persons with diabetes. Diabetes Educ. 2004;30:112-25.

22. Fisher WA, Kohut T, Schachner H, Stenger P. Understanding self-monitoring of blood glucose among individuals with type and type 2 diabetes: an information-motivation-behavioral skills analysis. Diabetes Educ. 2011;37:85-94.
23. Langendam M, Luijf YM, Hooft L. et al. Continuous glucose monitoring systems for type 1 diabetes mellitus. Cochrane Database Syst Rev. 2012:1:CD008101.

24. Nardacci EA, Bode BW, Hirsch IB. Individualizing care for the many: the evolving role of professional continuous glucose monitoring systems in clinical practice Diabetes Educ. 2010:36 (Suppl 1):4S-19S; quiz 20S-21S

25. Heinemann L, Franc S, Phillip M. et al. Reimbursement for continuous glucose monitoring: a European view. J Diabetes $S c i$ Technol. 2012;6:1498-502

26. Haak T, Hanaire H, Ajjan R, et al. Flash glucose-sensing technology as a replacement for blood glucose monitoring for the management of insulin-treated Type 2 diabetes: a multicenter, open-label randomized controlled trial. Diabetes Ther. 2017;8:55-73.

27. Palmer AJ, Roze $S$, Valentine WJ, et al. The CORE Diabetes Model: projecting long-term clinical outcomes, costs and costeffectiveness of interventions in diabetes mellitus (types 1 and 2) to support clinical and reimbursement decision-making. Cur Med Res Opin. 2004;20 (Suppl 1):S5-26.

28. McEwan P, Foos V, Palmer $\mathrm{LL}$, et al. Validation of the IMS CORE Diabetes Model, value Health. 2014:17:714-24.

29. Kiadaliri A, Clarke PM, Gerdtham UG, et al. Predicting changes in cardiovascular risk factors in type 2 diabetes in the postUKPDS era: Iongitudinal analysis of the Swedish nationa diabetes register. Diabetes Res. 2013;2013:241347.

30. Intensive blood-glucose control with sulphonylureas or insulin compared with conventional treatment and risk of complications in patients with type 2 diabetes (UKPDS 33). UK Prospective Diabetes Study (UKPDS) Group. Lancet. 1998:352:837-53

31. Stratton IM, Adler Al, Neil HA, et al. Association of glycaemia with macrovascular and microvascular complications of type 2 diabetes (UKPDS 35): prospective observational study. BMJ. 2000:321:405-12.

32. World Health Organization. Mortality Database. Available at: www.who.int/healthinfo/mortality_data/en/ (accessed 15 July 2014).

33. Läkemedelsförmånsnämnden. Läkemedelsförmånsnämndens allmänna råd om ekonomiska utvärderingar. 24-4-2003. [Medical Benefits Board. Medical Benefits Board General Advice for Economic Evaluations.

34. Hayes AJ, Leal J, Gray AM, et al. UKPDS outcomes model 2: a new version of a model to simulate lifetime health outcomes of patients with type 2 diabetes mellitus using data from the 30 year United Kingdom Prospective Diabetes Study: UKPDS 82. Diabetologia. 2013:56:1925-33.

35. Abbott Diabetes Care. REPLACE trial data on file. 2016.

36. Clarke $P$, Gray $A$, Holman $R$, et al. Estimating utility values for health states of type 2 diabetic patients using the EQ-5D (UKPDS 62). Med Decis Making. 2002;22:340-9.

37. Edridge CL, Dunkley AJ, Bodicoat DH, et al. Prevalence and incidence of hypoglycaemia in 532,542 people with type 2 diabetes on oral therapies and insulin: a systematic review and meta-analysis of population based studies. PLOS One. 2015;10:e0126427.

38. Skåne, Södra regionvårdnämnden. Regionala priser och ersattningar for sodra sjukvardsregionen 2014. Available at: www.skane.se/Upload/Webbplatser/Sodra\%20 regionvardsnamnden/prislista/2014/helaprislistan2014.pdf (accessed: 2015).

39. Jonsson L, Bolinder B, Lundkvist J. Cost of hypoglycemia in patients with type 2 diabetes in Sweden. Value Health 2006;9:193-8.

40. Anderson S, Høgskilde PD, Wetterslev 」, et al. Appropriateness of leaving emergency medical service treated hypoglycaemic patients at home: a retrospective study. Acta Anaesthesiol scand 2002:46:464-8.

41. DCCT Research Group. Epidemiology of severe hypoglycemia in the Diabetes Control and Complications Trial. Am J Med. 1991;90:450-9

42. TLV Drug database. www.tlv.se/beslut/sok/lakemedel/ (accessed 30 April 2013).

43. Organization for Economic Co-operation and Development (OECD), Consumer price index (all items) for Sweden. Available at: www.scb.se/hitta-statistik/sverige-i-siffror/samhalletsekonomi/prisernas-utveckling/ (accessed 30 September 2015)

44. Lauridsen JT, Lonborg J, Gundgaard J, Jensen HH. Diminishing marginal disutility of hypoglycaemic events: results from a time trade-off survey in five countries. Qual Life Res. 2014:23:2645-50.

45. Matza LS, Stewart KD, Davies EW, et al. Health state utilities associated with glucose monitoring devices. Value Health 2017;20:507-11

46. Meng J, Casciano R, Lee YC, et al. Effect of diabetes treatment-related attributes on costs to type 2 diabetes patients in a real-world population. J Manag Care Spec Pharm. 2017;23:446-52

47. Meyers JL, Parasuraman S, Bell KF, et al. The high-cost, type 2 diabetes mellitus patient: an analysis of managed care administrative data. Arch Public Health. 2014;72:6.

48. O'Connor CM, Whellan DJ, Lee KL, et al. Efficacy and safety of exercise training in patients with chronic heart failure: HF-ACTION randomized controlled trial. JAMA. 2009;301: $1439-50$

49. Dunn T, Xu Y, Hayter G, Ajjan RA. ATTD 2017. Real world flash glucose monitoring patterns and associations between selfmonitoring frequency and glycaemic measures: a European analylsis of over 60 million glucose tests. Diab Res Clin Pract. 2018; 137:37-46

50. Yu S, Varughese B, Li Z, et al. Healthcare resource waste associated with patient nonadherence and early discontinuation of continuous glucose monitoring in real-world settings: a multicountry analysis. Diab Technol and Ther 2018;20:421-7

51. Children with Type 1 Diabetes. Dexcom G5 vs Freestyle Libre 2016. 2016. Available at: http://childrenwithtype1diabetes.org/ dexcom-g5-vs-freestyle-libre-2016 (acessed 24 June 2018).

52. Bilir SP, Li H, Wehler EA, et al. Cost effectiveness analysis of a flash glucose monitoring system for type 1 diabetes (T1DM) patients receiving intensive insulin treatment in Europe and Australia. Value in Health. 2016:19:A697-8.

53. Twigg SM, Kazemi MH, Craig ME. Flash continuous glucose monitoring and its IMPACT to REPLACE blood glucose monitoring in the management of Type 1 and Type 2 diabetes US Endocrinology. 2017;13:57-62.

54. Persson U. Value \& Valuation of Health Technologies The Swedish Experience. The Swedish Institute for Economics (IHE), Zurich, 2010. Available at: www.swisshta.ch/index. php/Internationale_Erfahrungen.html?file=tl_files/ SwissHTA/documents/Workshop_11_2010/Praesentationen/ Praesentation_Persson_20101005.pdf (accessed 24 June 2015).

55. Bolin K, Sandin R, Koltowska-Haggstrom M, et al. The costeffectiveness of growth hormone replacement therapy (Genotropin) in hypopituitary adults in Sweden. Cost Eff Resour Alloc. 2013;11:24

56. European Central Bank. Euro to Swedish Kroner exchange rate. Available at: www.ecb.europa.eu/stats/exchange/ eurofxref/html/eurofxref-graph-sek.en.html (accessed 31 July 2018

57. Sreenan $\mathrm{S}$, Andersen $\mathrm{M}$, Thorsted BL, et al. Increased risk of severe hypoglycaemic events with increasing frequency of non-severe hypoglycaemic events in patients with type 1 and type 2 diabetes. Diabetes Ther. 2014;5:447-58.

58. Munshi MN. Cognitive dysfunction in older adults with diabetes: what a clinician needs to know. Diabetes Care. 2017:40:461-7.

59. Hsu P-F, Sung S-H, Cheng H-M, et al. Association of clinical symptomatic hypoglycaemia with cardiovascular events and total mortality in type 2 diabetes: a nationwide populationbased study Diabetes Care. 2013:36:894-900

60 Goto A, Aran OA, Goto M, et al. Severe hypoglycaemia and cardiovascular disease: a systematic review and meta-analysis with bias analysis. BMJ 2013:347:9-19.

61. Currie $\mathrm{CJ}$, Morgan $\mathrm{CL}$, Poole $\mathrm{CD}$, et al. Multivariate models of health-related utility and the fear of hypoglycaemia in peopl with diabetes. Curr Med Res Opin. 2006;22:1523-34.

62. Haak T, Hanaire H, Ajjan R, et al. Use of flash glucose-sensing technology for 12 months as a replacement for blood glucose monitoring in insulin-treated type 2 diabetes. Diabetes Ther. 2017;8:573-86. 